\title{
UM TICO PARA FORMAR ADULTOS
}

\author{
A SMALL TO FORM ADULTS
}

Edson Wilson Mendes de Almeida'

RESUMO: A revista Tico-Tico foi lançada em 1905, com a intenção de ensinar as crianças. Era publicada como um suplemento na revista $O$ Malho, mas que poderia ser adquirida separadamente. Em seu interior eram encontradas histórias em quadrinhos, inicialmente decalcadas dos jornais estadunidenses e posteriormente feitas por artistas nacionais, lendas e contos, galeria de fotos dos leitores, além das seçôes do Dr. Sabe-tudo e das Liçôes do Vovô. A publicaçáo procurou desenvolver o hábito de leitura e gosto pelo conhecimento dos pequenos, que até então não tinham uma obra voltada para eles. O período estudado do periódico (19201922), perfaz outro movimento singular na época, o desenvolvimento da Semana de Arte Moderna de 1922, em São Paulo.

PALAVRAS-CHAVE: Periódico. Quadrinhos. Leitor.

ABSTRACT: Tico-Tico magazine was launched in 1905 with the intention of teaching children. It was published as a supplement in O Malho magazine, but could be purchased separately. In the interior were found comics, initially copied of the American newspapers and later made by national artists, legends and tales, photo gallery of the readers, besides the sections of Dr. Sabetudo and the Lessons of the Grandpa. The publication sought to develop the habit of reading and taste for the knowledge of the little ones, who until then had not had a work turned to them. The studied period of the periodical (1920-1922), marks another unique movement at the time, the development of the Modern Art Week of 1922 in Sáo Paulo.

KEYWORDS: Periodic. Comics. Reader.

\section{INTRODUÇÃO}

As histórias em quadrinhos nasceram nos jornais estadunidenses de Nova York no final do século XIX com o objetivo de atrair novos leitores. As duas criações de Richard F. Outcault mais conhecidas são The Yellow Kid, em 1986, e Buster Brown, em 1902. A primeira narra as aventuras de um grupo de crianças no bairro Hogan's Alley, enquanto a segunda as aventuras de um menino típico, pertencente ao que ficou conhecido como

Mestrando em História no PPGH da Universidade Federal de Goiás (UFG). Graduado em História e PósGraduado em História Cultural pela Universidade Estadual de Goiás (UEG). E-mail: prof.edson.wilson@ hotmail.com . 
W.A.S.P., White, Anglo Saxonic, Protestant (Branco, Anglo Saxônico, Protestante). As duas obras são distintas e singulares, e mesmo tendo como personagem principais dois meninos, que em certos momentos faziam estripulias, estão longe de ser semelhantes. As aventuras do menino amarelo eram mais críticas, e talvez por esse motivo náo tivessem alcance nas terras brasileiras. Buster Brown foi lançado no Brasil, na revista Tico-Tico, com um alcance sem igual, porém com outro nome.

Figura 1: Buster Brown e seu fiel cão Tige

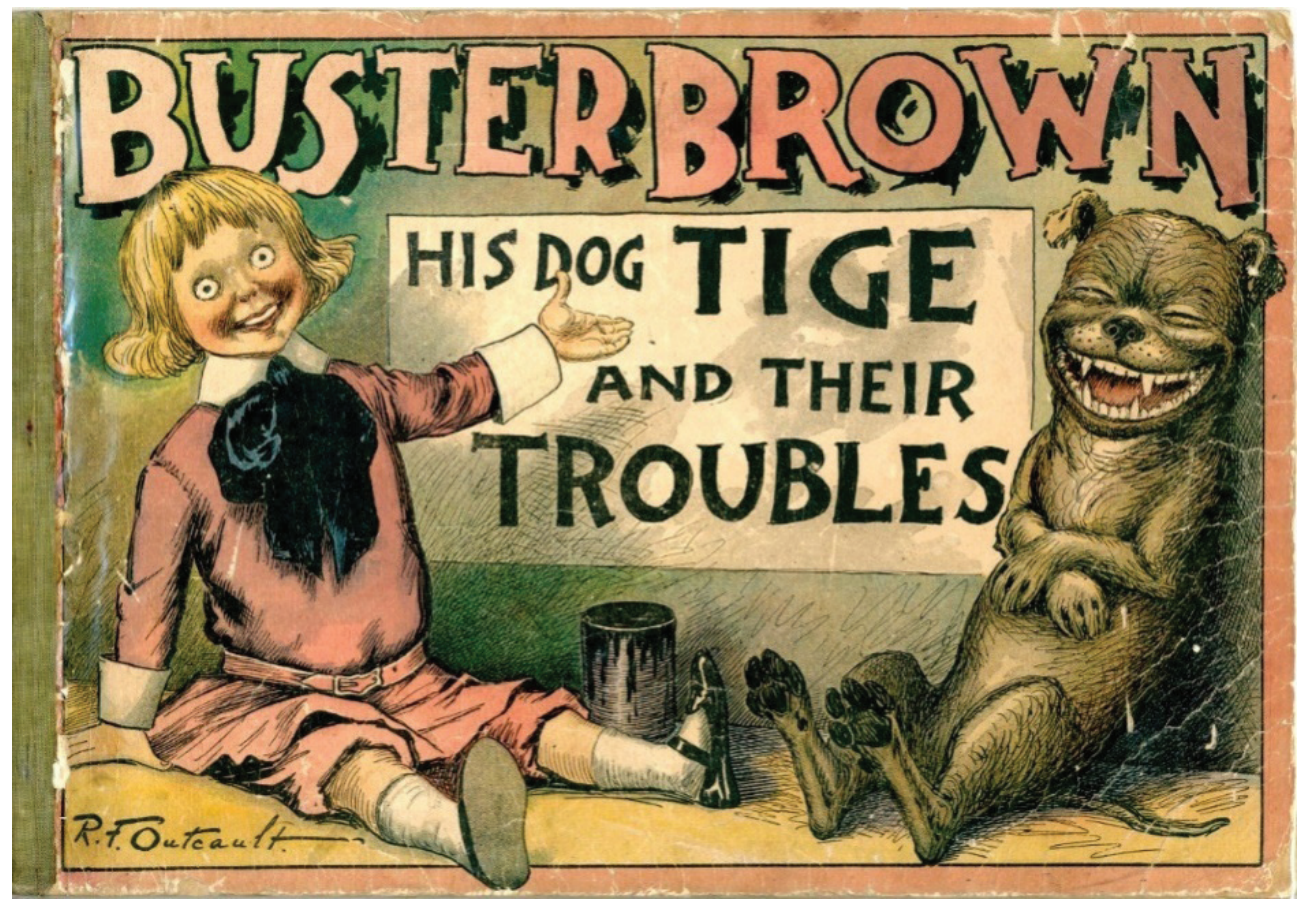

Fonte: Disponível em: https://michiganhumane.wordpress.com/2015/04/27/celebrating-the-pit-bull-tige/

Os autores nacionais se valiam da técnica de decalcar a obra original, publicada no The New York Herald, e assim, conseguiam modificá-la e apresentar uma realidade mais próxima à nacional. Buster Brown foi rebatizado para Chiquinho, assim como seu fiel cão, Tige, para Jagunço, que servia muitas vezes de consciência de seu dono, o primeiro cáo falante das histórias em quadrinhos. O cenário suburbano e classe média estadunidense foi trocado pelo Rio de Janeiro. O personagem ganhou o público e se manteve nas páginas da revista Tico-Tico por décadas. Em 1915, Chiquinho ganhou um parceiro em suas aventuras, o jovem Benjamim, criação de Luís Gomes Loureiro, que Silva (2005, pp. 3738) o define como "um 'pretinho de recados' que era muito comum naqueles tempos, nos lares brasileiros”. Benjamim apreciava as traquinagens do jovem branco. Mesmo o autor mudando de jornais e levando seu personagem com ele, no Brasil, nada foi alterado. Com o cancelamento do jovem, por opção de Outcault, a revista nacional não parou de lançar histórias, neste período, os artistas nacionais já faziam suas ilustrações e não estavam mais dependentes dos decalques. 
Figura 2: Chiquinho, seu fiel cão Jagunço e Benjamim



Fonte: Disponível em: https://omelete.uol.com.br/quadrinhos/artigo/ ivoce-sabia-turma-da-monicai-uma-revista-de-quadrinhos-com-finalidades-educativas/

A revista Tico-Tico nasceu como um suplemento que acompanhava o jornal O Malho, de Luís Bartolomeu de Souza e Silva em 1905, toda quarta-feira. A mesma utilizou como molde publicações francesas e estadunidenses, principalmente no modelo gráfico da revista francesa La Semaine de Suzette.

Em seu relato, Diamantino Silva (2005, p. 37) revela que em "um ano após seu lançamento, O Tico-Tico, já alcançava a expressiva tiragem de trinta mil exemplares”. A obra tinha a intenção de ser exclusiva aos pequenos, os ticos, que sofriam por não ter algo especifico e destinado a eles. Livros, músicas, festas e outras atividades sociais, na interpretação de Merlo $(2004,03)$ "eram apenas voltadas ao público adulto, urbano, politizado, elitista e intelectualizado". Assim, Hansen, apresenta "a imagem que se tinha da criança era, em larga medida, de 'homem pequeno', o até mesmo de homem incompleto", um universo fechado e concentrado (2007, p. 16).

Uma publicação como a revista Tico-Tico não tinha a intenção de apenas levar o "mundo adulto" para as crianças, mas sim, apresentar às crianças uma possibilidade de serem elas mesmas, como bem colocado em seu editorial na edição inaugural de 1905:

Todos amam as crianças; não ha poeta que não celebre sua innocencia e a sua belleza... Entretanto, caso singular! nada se faz em favor dellas, para divertil-as, para distrahir e encantar a sua existência. Não organisamos festas alegres, em que ellas possam folgar e rir liberdade e não lhe damos uma litteratura especial, simples (...) ao alcance da sua inteligência. Ao contrario disso, as festas em que as crianças figuram são destinadas a divertir... os marmanjos, marchando ao sol em batalhóes obrigadas a uma disciplina e a uma tenue que as fadiga e aborrece, ou representando comedias e dizendo monólogos que não compreendem, ellas vão a essas festas como a um sacrifício e a um castigo ${ }^{2}$ (Tico-Tico, 1905, p. 3).

$2 \quad$ Optou-se por manter a grafia da época nas citações. 
A seção Tico-Tico Mundano trazia as açóes dos ticos em sociedade, como batismos, nascimentos, aniversário, leilóes para as crianças, outro ponto forte eram as fotos das crianças enviadas para serem publicadas na revista, na galeria d'o Tico-Tico. Mas o periódico não se limitava a somente um personagem, Chiquinho, nela eram encontrados: Reco-Reco, Bolão e Azeitona, Zé Macaco e Faustina, Tinoco, Caçador de Feras, Bolinha e Bolonha, Carrapicho e Lamparina. As seçóes procuravam ensinar as crianças onde se podia encontrar as Liçóes do Vovô, Correspondências do Dr. Sabe-tudo e Histórias e Lendas.

Figura 3: Logo da Primeira Edição de 11 de outubro de 1905

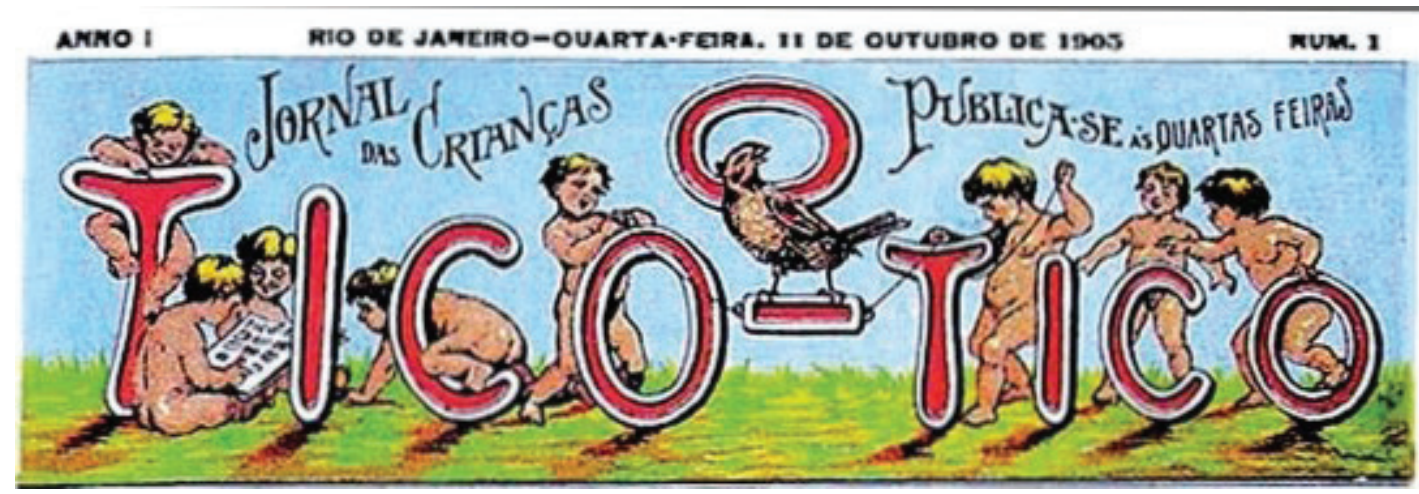

Disponível em: http://lagartonegroblog.blogspot.com.br/2013/12/rod-gonzales-os-primeiros-superherois.html

\section{QUADRINHOS, NARRATIVAS E LEITOR}

Em sua introdução sobre narrativas gráficas, Einser (2005, p. 7), comenta o motivo dos quadrinhos sofrerem preconceito, "as revistas em quadrinhos são de fácil leitura, sua utilidade vem sendo associada a uma parcela da população de baixo nivel cultural e capacidade intelectual limitada". Porém esta facilidade pode ser um recurso excepcional no quesito pedagógico, não apenas com as crianças, mas também com adultos na sua aprendizagem. A narrativa que o autor deseja imprimir a sua obra se torna o grande diferencial, pois os quadrinhos são nada mais, nada menos que uma plataforma, podendo ser usada para ensinar, entreter, alienar, disseminar o preconceito ou combater as indiferenças.

Analisando uma história, podemos ter vestígios de uma época, e nas histórias do TicoTico, a formaçáo da criança nos abre frestas com a linguagem usada. O ficcional pode ser mais real que a própria realidade, devido a sua busca de convencer o leitor da verossimilhança existente entre ele e a obra. Esta condição de aproximação tornou-se fundamental para o sucesso de Chiquinho, de estadunidense típico para o típico brasileiro de classe média. Segundo Luyten (2005, 45); "Luis Gomes Loureiro, 'pai' do Chiquinho no Brasil, deu-lhe características locais e argumentos brasileiros", rebatizando o personagem. O jovem loiro com uniforme de marinheiro ganhou o público, não apenas por suas traquinagens, mas sim por se parecer com um menino normal e comum, distante da versão engessada que os adultos tinham das crianças. 
Após as criações de Richard F. Outcault, os personagens infantis multiplicaram-se. Os sobrinhos do Capitão (The Katzenjammer Kids, no original), em 1897, de Rudolph Dirks; Little Nemo in Slumberland, em 1905, de Windsor Mc Cay; Bécassine de GauthierMaurice Languereau, em 1905, aparecem no La Semaine de Suzette, para citar alguns que ganharam o gosto do público, tanto em seus países quanto fora dele. Todas com características próprias, mas o que chama atenção são as artimanhas dos jovens, o modo criança de ser, levadas e criativas.

A narrativa era inocente, ingênua e sem dualismo de personalidades, as traquinagens não tinham a intenção de maldade pura e vil. Assim sendo, Sevcenko (2003, 20), afirma que "todo escritor possui uma espécie de liberdade condicional de criação, uma vez que os seus temas, motivos, valores ou revoltas sáo fornecidos ou sugeridos pela sua sociedade e seu tempo". Esta colocação aproxima o público da obra, na qual a narrativa nos remete à forma em como as histórias em quadrinhos ganharam o gosto do grande público, pois sendo uma cultura de massa e destinada a todas as classes, a obra é posta ao alcance de todos, e no caso da revista, o primeiro contato viria com a aquisição monetária. Porém, uma pessoa poderia ter acesso de outras formas, por empréstimo ou por conta de uma vez consumida, poderia ser lançada ao lixo, mas o sucesso depende da aprovação e consumo pecuniário dela. Uma curiosidade sobre a maioria destes primeiros personagens é que são masculinos, quando se encontrava uma moça, eram em geral pudicas, recatadas, bem vestidas e distantes das artimanhas e espertezas das suas contrapartes.

Figura 4: Os gêemeos Hans e Fritz da publicação Os Sobrinhos do capitão de Rudolph Dirks

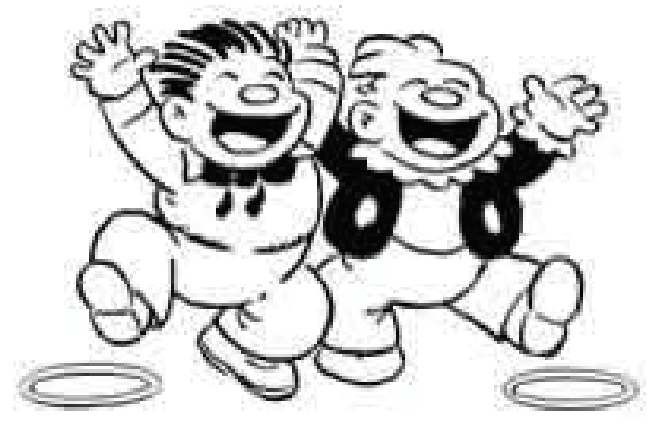

Disponíveis em: http://hqmaniacs.uol.com.br/Os_Sobrinhos_do_Capitao_em_edicao_de_luxo_9921.html

Para Eisner o diferencial entre as mídias, filmes, textos e quadrinhos, ao qual o autor irá chamar de arte sequencial, está centrada na figura do leitor e a sua interação com as obras, neste sentido, o autor observa algumas divergências, como um breve conhecimento prévio acerca do assunto e o ritmo da obra $(2005,73)$. Segundo o autor, nos filmes: “o público é transportado por meio da narrativa. Ela não deixa tempo para contemplar ou saborear as passagens, o observador é um espectador da realidade artificial' (EISNER, 2005, p. 73).

$\mathrm{O}$ cinema adentrou em várias temáticas em sua trajetória, abrindo espaços e vencendo resistências, mas vale lembrar que náo estamos falando da modernidade ou tecnologia existente nos dias atuais, a análise se encontra nos cinemas, e náo em smartphones, 
computadores ou qualquer outra plataforma de exibição onde o expectador pode parar a exibição e retornar posteriormente. Por exemplo, para Eisner (2005, p. 73): "Textos: a aquisição exige, requer a capacidade de ler, o que envolve pensamento, participação e lembranças... os leitores convergem palavras em imagens". Ao se trabalhar com palavras, signos codificados, que necessitam serem decodificados, a literatura exige do leitor um conhecimento prévio acerca de alguns do assunto, é deveras complexo explicar algo abstrato para uma pessoa que nunca teve contato, seja visual ou tátil, com o que está sendo descrito. Eco "esclarece que, para que haja uma troca de informaçóes entre o autor e o leitor, é necessária uma enciclopédia, ou seja, uma bagagem de conhecimento suficiente para o entendimento da narrativa" (ECO apud BARBOSA, 2009, p. 104).

Segundo Eisner, "a aquisiçáo dos quadrinhos exige menos do que o texto porque as imagens são fornecidas. A qualidade da narrativa depende da disposição de texto e imagem, espera-se que o leitor participe" (2005, p. 73). União de imagético e textual fornece ao leitor uma gama de possibilidades para uma melhor compreensáo da narrativa posta em quadros sequenciais. Para as crianças em período escolar, o auxílio dado ao cognitivo se faz presente e atuante.

As histórias em quadrinhos são antes de tudo uma narrativa, podendo ser apenas imagética em alguns casos, mas também escrita. A revista Tico-Tico usava de todas estas características para levar seu conteúdo aos leitores. Vergueiro $(2009,114)$ afirma que: "cultivava o objetivo de formar um determinado tipo de cidadão e louvar um padráo de comportamento especifico, aquele que ajudaria a construir a sociedade ideal imaginada pelos diretores da revista e pelas classes sociais que eles representavam". Na maioria das histórias, temos a parte gráfica com a explicação da cena ou com a fala de algum personagem abaixo da imagem, assim como comenta Silveira sobre os primeiros anos das histórias em quadrinhos:

Tal narrativa se assemelha com as histórias ilustradas de Hudolf Topffer e Wilhelm Bush, entre outros, utilizando as imagens fragmentadas seguidas de legendas, que guiavam toda a história. Essas histórias representam os primeiros passos da narrativa gráfica na imprensa e serviram de base para o desenvolvimento da linguagem dos quadrinhos como hoje a conhecemos $(2013$, p. 2).

Em algumas aventuras temos os famosos balóes nas falas dos personagens, mas as explicações não deixam de existir, esta união entre texto e imagem é a base das revistas em quadrinhos, o leitor não precisa possuir um cabedal de informaçóes para entender uma obra. O ritmo de obra é feito por ele, podendo "ler" as imagens antes de ler a parte escrita.

Como colocado por Diamantino Silva, a publicação tinha um objetivo claro e específico, bem colocado por Hansen (2007, p. 17):

Ainda que fosse destinada a cumprir uma função pedagógica, chegando inclusive a estimular o aprendizado da leitura como informam muitas cartas publicadas pela revista, o periódico foi principalmente um empreendimento comercial que obteve enorme sucesso entre o público infantil.

Neste sentindo, alocamos a publicação como um produto da cultura de massa, ao qual, o público faz toda a diferença. Segundo Merlo (2004, p. 09): 
No entanto, é importante ressaltar que o público variado e extenso de O Tico-Tico - pois tanto crianças, como adultos se deliciavam com suas páginas - era formado basicamente de leitores de poder aquisitivo e que tivessem o raro acesso à educação existente no Brasil do início do século XX.

O alvo é a criança, sem sombra de dúvida, entretanto, alguns adultos poderiam fazer uso, visto que a revista tinha uma preocupação em informar seu público sobre diversos assuntos, o que poderia interessar a um adulto. Augusto $(2005,7)$ revela um "Ruy Barbosa, que já era cinquentão no começo do século, encontrou nas coloridas páginas do Tico-Tico relaxante ideal para a azáfama politica e as espessas leituras a que diariamente era submetido", porém o fato do leitor ser obrigatoriamente letrado, pode ser uma afirmativa conduzida devido ao estilo da publicação.

Para apreciar todas as partes do periódico, existe a necessidade do domínio de codificação dos códigos de escrita, mas as iletradas, seja por conta da tenra idade ou por não ter conhecimento ou domínio sobre a escrita nacional, poderia apreciar uma parte da obra, ficando restritas a narrativa imagética, ilustrativa. A colocação de Silveira reforça a questão $(2013,5)$ : "Até então o texto mantinha uma relação de redundância comum nas $H Q s$, uma vez que a legenda (texto posto em uma caixa de diálogo logo abaixo da imagem) era praticamente autônoma e as imagens continham a mesma mensagem trazida no texto".

Para que se tenha uma história em quadrinhos, se faz necessário a sequência de dois ou mais quadros. McCloud oferece a definição precisa ao colocar nestes parâmetros a arte sequencial: "Imagens pictóricas e outras justapostas em sequência deliberada destinadas a transmitir informaçóes elou a produzir uma resposta no espectador” (2005, 9). Com esta observação em mãos, um quadrinho pode ser dois ou mais quadros com uma sequência, sem a necessidade da escrita, porém se ela estiver, deve reforçar a continuidade da narrativa.

Distante da formação nacionalista e regional, a qual alguns artistas tinham no período, a revista procurava formar futuros cidadãos descentes e distintos, habilitados para discursar acerca de vários assuntos. Vergueiro estabelece que "tinha histórias de conteúdo moral que visava ensinar aos meninos de sua época como as crianças boas deveriam se comportar" $(2009,88)$. Este alcance se mostra amplo no quesito território nacional, e a melhor forma de apresentar esta colocação se encontra na sessão galeria d'o Tico-Tico, com fotos dos ticos de várias regióes do país. Porém vale salientar alguns detalhes que possuem uma relevância sobre as crianças apresentadas na sessão: a grande maioria dos pequenos são brancos.

Segundo Hansen; "O público passa a ser considerado, ele mesmo, uma criação dos processos de produção e circulação de bens culturais" (2016, 14). Podemos, entretanto, afirmar que era uma escolha dos editores da revista, a afirmação de que não tínhamos indivíduos afrodescendentes com condiçóes de serem retratadas é infundada. Para a definição da classe social, seria necessário um estudo mais profundo, porém devemos acreditar que muitos são de classes média e alta, devido aos custos de vestimenta e produção fotográfica, vide que ainda possuía um alto custo. As crianças, em vários retratos, estão vestidos como pequenos adultos e apresentam vestimentas pouco usuais para o dia a dia. Neste ponto a observação de Hansen $(2007,12)$ sobre a condição da criança na sociedade brasileira 
ter "adquirido maior valor na sociedade e na família, da qual passam a ser o centro e para a qual também servem como uma espécie de vitrine, mostrando o seu grau de adequação ao novo modelo de civilidade" faz um cruel sentido.

Na edição do Ano XVII, de 22 de novembro de 1922, as crianças que tiveram suas fotos publicadas eram de Porto Alegre, Rio Grande do Sul, Pouso Alegre, Minas Gerais e incluindo uma de Lisboa, deixando claro a amplitude da publicação. Segundo Gomes e Hansen (2016, 9): "as práticas de mediaçóes culturais podem ser exercidas por um conjunto diversificado de atores, cuja presença e importância nas várias sociedades e culturas têm grande relevância, porém nem sempre reconhecida". A revista Tico-Tico agregava algo inédito no Brasil, uma revista voltada para a educação de jovens de forma lúdica, abrangendo o território nacional.

\section{TICO-TICO: FORMADOR DE IDENTIDADE}

Em geral, intelectual mediador são homens ou mulheres que patrocinam, atuando em alguns casos como mecenas, lançando ou mesmo divulgando uma obra, um artista ou um movimento. Mas, no caso da revista Tico-Tico, vamos considerar que sua posição fez o papel de um mediador, visto que sua função, além de obter sucesso financeiro, foi o de ensinar as crianças de forma lúdica, construindo uma identidade nacional. Para Hansen (2016, 9): "outros mediadores culturais podem ser identificados como leitores, contadores de história, guias de instruçóes, pais e outros agentes educadores encarregados da socialização de crianças e jovens em diversas situaçôes”. Trazendo Vergueiro (2005, p. 118) para reforçar este ideal formativo, pois a revista "desde seu início, inclusive, a direção do seminário buscou também enfatizar esse aspecto de elemento complementar da educação formal". Longe dos quadrinhos, as seções "Correspondência do Dr. Sabe-tudo" e "As liçôes do Vovô", procuravam ensinar as jovens almas, ou tirar dúvidas sobre os mais variados temas.

Nas Correspondências do Dr. Sabe-tudo as mais variadas perguntas eram enviadas por seus leitores à redação, que se propunha respondê-las. Vergueiro (2005, p. 116) relata a abrangência de assuntos tratados na sessão "conhecimentos gerais, moda, beleza, esportes, tratamento de saúde, exercícios físicos, etiqueta, orientação de leitura, culinária, e indicação de escolas e estudos". Como um exemplo da amplitude da revista, selecionamos três respostas aos questionamentos da revista, de 3 de maio de 1922, de Rosa Bianca de Santos, Nenê do Rio e de Aninoel da Bahia:

ROSA BIANCA (Santos) - $1^{\circ}$ - Remedio para queda de cabelo e caspa: Quina Panamá ou Petroleo Olivier. $2^{\circ}$ - O horoscopo de 22 de Setembro é este: A mulher será tímida e casta, com bonitos olhos, feiçóes regulares e o rosto oval. Será boa mãe de família, piedosa, delicada e compassiva. Casará cedo e rica terá mais filhas que filhos, as quaes, como sua mãe, serão de uma beleza rará.

NENÊ (Rio) - Palavra de honra como cheguei a duvidar do que escreveu! Pois se já empregou pomada mercurial, mercurio em po com álcool, etc, etc, - como é que ainda não extinguiu esses parasitas de sua menina?!... Enfim, póde ser. E nesse caso, abandone o tratamento heroico e passe a usar um óleo qualquer na cabeça da paciente. Limpeza constante e meio oleosos - eis o remédio eficaz. 
ANINOEL (Bahia) - $1^{\circ}$ - Quanto ás espinhas, faça o tratamento indicado a localidade, na primeira resposta. $2^{\circ}$ - O remedio eficaz contra a caspa é lavar a cabeça com carbonoto de magnésia e usar o Petroleo Olivier, ou Jardy, ou Quina Panamá, de Silva Araujo. E, se puder tomar banhos de mar ou, pelo menos, usar loçôes diárias de agua do mar, acabará de vez com a caspa, sem outro auxilio. $3^{\circ}$ - Não lhe posso dar os horóscopos. Esquece-se de dizer se eram para homem ou para mulher. Só falou em pessoas... (Dr. Sabe-tudo, 1922, 16).

Observamos que em nenhum momento o Dr. Sabe-tudo recomenda aos leitores procurarem um médico para fazer exames, algo fundamental nos dias atuais. Ele se baseava nas descriçóes dos leitores acerca das suas enfermidades e indicava os remédios a serem tomados. Outro fato curioso está no medicamento sugerido, pois aparecia nos anúncios na própria revista.

Na seção "As liçóes do Vovô", um nobre senhor respondia sobre os mais variados assuntos, fazendo uso da experiência e conhecimento que tal figura possui, e para criar um sentimento de intimidade familiar, chamava todos os leitores de netinhos. Segundo Vergueiro:

Elaboradas de forma carinhosa, como uma conversa ao pé do ouvido, as Liçôes enfatizavam modelos desejáveis de comportamento, enfocando aspectos da sociedade brasileira sob o ponto de vista social, político, econômico e cultural e discorriam sobre temáticas ligadas ao currículo educacional formal (2005, p. 116).

Na edição de 06 de janeiro de 1920, o vovô explica aos netinhos sobre como uma planta se alimenta, o fato curioso é sobre quando uma planta bebe mais água:

A planta, meus netinhos, bebe agua lentamente de manhã cedo, quanto o tempo está fresco, depois vae bebendo mais depressa, a proporção que há mais luz e o sol se vae tornando mais quente: ao partir do meio da tarde, quando a temperatura vae baixando, diminue a quantidade d'agua e á noite quase que não bebe agua nenhuma (As liçôes do Vovô, 1920, p. 5).

Na edição de, 26 de abril de 1922, a vovó comenta uma experiência do netinho Bento, que foi à praia e lhe questionou sobre os animais que se parecem com flores. No caso, a gentil senhora discorre sobre anêmonas e cravos do mar: "seu tamanho attinge, ás vezes, á grossura do punho de um adulto e as pétalas, que tanto encanto dão aos nossos olhos maravilhosos, são tentaculos que cercam a abertura central que o corpo do animal possue" (Liçóes do Vovô, 1922, p. 5).

Estas duas seçóes foram as mais tradicionais e frequentes nas ediçóes, entretanto os escoteiros ganharam uma seção, a partir da edição Anno XVI, de 28 de dezembro de 1921. A abertura da seção iniciava fazendo lamento da lacuna que existia no jornalzinho, pois "como vós sabeis, educa e instrui brincando; era, pois, lastimável, que ainda não houvessemos chamado a nós tão excellente auxiliar" (1921, p. 14). A seção era dividia em três partes: I não tinha a pretensão de ser um guia, porém tratava de técnicas e problemas ao qual um escoteiro poderia encontrar; II - as correspondências, dúvidas dos leitores; III - notícias, organizações, reunióes e festas realizadas pelos vários grupos que tinham no Brasil.

$\mathrm{Na}$ seção Histórias e Lendas eram encontradas os contos e lendas, presentes no periódico. Se valia tanto de contos clássicos, quanto de escritos inéditos, porém, todos 
sempre voltados para os ticos, tendo sempre um carácter moralizante, assim como nos quadrinhos, e poucas ligaçóes com patriotismo. Como já dito, o importante era formar um cidadão, não necessariamente um patriota. Segue uma pequena lista de obras publicadas no ano de 1922. A lebre e o ouriço ${ }^{3}$; A princesa e a rã; ${ }^{4} \mathrm{~A}$ arvore de natal; ${ }^{5}$ A vingança da infanta; ${ }^{6}$ Quem com ferro fere...; $;^{7}$ Os grandes animaes; ${ }^{8}$ O lago azul, ${ }^{9}$ escrito por Paulo Sauro. Fazendo uso das narrativas de contos, podemos observar a preocupação de dispor uma situação na qual um personagem pode tirar proveito de uma situaçáo para assim obter algum sucesso, o que posteriormente sua açáo fraudulenta lhe colocará em uma situação embaraçosa. O jovem leitor é ensinado a agir sempre fazendo o bem, para não ser punido por golpes ou trapaças. Mas esta colocação também era vista nas aventuras dos personagens das histórias em quadrinhos, quando aprontavam e eram pegos.

$\mathrm{Na}$ edição de novembro de 1920, na sessão "A melhor propaganda do Brasil”, ao comentar sobre as ediçóes de setembro e outubro, da Illustraçáo Brasileira, temos uma colocação que melhor define a visão dos seus realizadores: "conta com a colaboração dos maiores escritores e artistas nacionais, honra o pais e, onde quer que vá, levará a melhor propaganda de nossa terra e da nossa gente". A preocupação seria a de elevar a condição do Brasil em países desenvolvidos.

Um pequeno fato curioso: quase todos os anos a luta contra os mosquitos se intensifica no território nacional. Uma luta incansável contra um inimigo diminuto, frágil, entretanto tão mortal e devastador, sendo que um deles ganhou um destaque em especial, o aedesegiptys, causador de moléstias nefastas sobre a população humana, que desconhece classe social, nível cultural, nacionalidade, etnias ou gênero sexual. Este vilão, já é conhecido de longa data, ou ao menos em partes. Na edição de 23 de fevereiro de 1921, os leitores são apresentados ao facínora, com seu ciclo de vida, foto em sua versão adulta e locais de procriação. Aqui, temos uma alfinetada no governo imperial, pois o autor da coluna inicia sua fala atacando os governos passados, " $H a ́$ cerca de uns vinte annos, os mosquitos não estavam sofisticadamente estudados" (Tico-Tico, 1921, p. 9). A revista procurava esclarecer onde estes seres tão vis se procriavam e como combatê-los, para que pudéssemos eliminá-los e salvar o mundo, até a próxima estação climática quente e chuvosa.

Os artistas da Semana de Arte Moderna de 1922 em São Paulo, procuraram integrar a sociedade brasileira, dar uma cara a nossa arte e assim, desvincular da arte vinda de outros países. Esta nacionalidade aproximava-se de um regionalismo, de um bairrismo

Anno XVII, Rio de Janeiro, quarta-feira, 3 de maio de 1922, no 865, p. 7.

Anno XVII, Rio de Janeiro, quarta-feira, 26 de abril de 1922, no 864, p. 9.

Anno XVII, Rio de Janeiro, quarta-feira, 19 de abril de 1922, no 862, p. 7.

Anno XVII, Rio de Janeiro, quarta-feira, 12 de abril de 1922, no 862, p. 9.

Anno XVII, Rio de Janeiro, quarta-feira, 1 de março de 1922, no 856, p. 9.

Anno XVII, Rio de Janeiro, quarta-feira, 22 de fevereiro de 1922, no 855, p. 9.

Anno XVI, Rio de Janeiro, quarta-feira, 7 de dezembro de 1921, no 844, p. 7. 
latente e vigoroso. Em terras não táo distantes, a revista Tico-Tico transformava a sociedade nacional, não falando aos grandes, mas aos pequenos e que ganhara força e respeito com o passar das edições semanais, sempre sendo lançado nas quartas-feiras. Nesta disputa de forças, temos o cidadáo brasileiro, formatado, moldado e elaborado, desde tenra idade, sob a égide da revista no modelo do cidadáo sem um patriotismo latente contra o nacionalismo patriótico regionalista, que procura integrar o todo sob sua bandeira.

\section{PARTINDO EM BUSCA DE UMA NACIONALIDADE}

A música Trem das Onze não é do período estudado, mas possui relaçáo com a questáo posta no término do parágrafo acima. Composta por Adoniram Barbosa e imortalizada pelo grupo de samba paulistano Demônios da Garoa relata a condição de um rapaz que reside em Jaçană, situado na zona norte da cidade de Sáo Paulo, porém não diz onde ele se encontra, mas ele enfatiza categoricamente que "Se eu perder esse trem /Que sai agora às onze horas / Só amanhã de manhâ". A música pertence ao cancioneiro popular brasileiro, ganhou um prêmio no Rio de Janeiro e é tida como uma das dez músicas mais populares de todos os tempos. Porém, algo pode às vezes passar despercebido, que a letra está ressaltando a condição de um paulistano, elevando sua condiçấo de pessoa sem muitos recursos a ser cantada como se ele fosse a maioria dos cidadáos brasileiros, como se todos ou a grande maioria não pudesse ficar um pouco mais de tempo com outra pessoa devido a condiçáo monetária. O regionalismo ou bairrismo paulistano adentrou as artes na Semana de Arte Moderna de Sáo Paulo em 1922, principalmente na literatura e nas artes plásticas e foi conduzido a todo o território nacional, como se fosse natural do brasileiro, o patriotismo cercado do sotaque paulistano integrava a tudo e a todos.

Em um país agrário, o industrialismo de São Paulo destoava da condição nacional. A luta pela modernizaçáo abateu o espírito paulista em se olhar como uma ponta de lança com forte tendência a elevar o nível da condição nacional. O desejo desbravador avançou em cada alma paulistana, com a intençâo clara de se observar como um ser iluminado pelo conhecimento e desenvolvimento. No Rio de Janeiro de 1822 ocorreu a independência política da nação, mas não ocorreu o desenvolvimento táo esperado, cem anos se passaram e o sonho da independência chegou à pauliceia. $\mathrm{O}$ modernismo avançará com força do ferro e aço, unido ao concreto, elevando a cidade, deixando para trás o agrário e buscando a industrialização.

O moderno se entende como o presente, e o Brasil não era moderno, náo era desenvolvido aos olhos da elite brasileira. Velloso explica que "o moderno necessita do antigo para adquirir sentido e apresenta-se como tal' (2010, p. 12). O passado estava associado e impregnado de atrasos, o passado imperial, à força dos escravos, ao analfabetismo, ao campo, e principalmente a decadente e obsoleta capital do país, Rio de Janeiro. Ao visto que São Paulo despontava como bastiáo da modernidade, segundo Pinto: "com seu dinamismo, suas fábricas seu progresso, espírito pragmático, sua realidade urbano-industrial, a 
incorporação das novas tecnologias da sociedade de massa e a imigração europeia representava a base" (2001, p. 436). Tornava-se, assim, o centro para se vencer o passado arcaico. Espíritos heroicos de um passado distante, precisavam fortalecer o ideal aventureiro desta capital da modernidade, se fazia necessário ajustar o passado com o presente, e neste ponto, o bandeirante aparecia como o grande herói, aquele que desbravava terras, avançava sobre um o sertão e vencia desafios.

Diferentemente da revista Tico-Tico, as elites paulistanas estavam inclinadas a delimitar uma unidade nacional, um modelo ao qual todos deveriam seguir, o ideário de formar um cidadão disciplinado não era o suficiente, se fazia necessário amoldar um cidadão brasileiro. Pinto declara que: "o coração do Brasil brasileiro e moderno seria São Paulo" (2001, 437). A regiáo paulista deveria seguir a frente e liderar a naçáo, com seu exemplo e determinação. Vide que Sáo Paulo sempre olhou para o sertão e não esperou do litoral o sucesso, do que vinha de fora, buscou o que tinha de melhor no Brasil para fazer sua fortuna. $\mathrm{O}$ desenvolvimento náo deveria ficar distante do poder criativo, o mundo cultural deveria largar a decrépita capital fluminense, aportar na moderna pauliceia e singrar em direçáo ao restante do Brasil, em seguida. Como se bem observado, uma parte deste sonho foi realizado, pois as principais editoras do país desde então se encontram na terra da garoa. Deixou-se para trás a Rua do Ouvidor, caminhando-se todos para a Avenida Paulista.

Os intelectuais se apegaram ao ideário, buscando inspiraçóes no modernismo que a metrópole bandeirante os apresentava. Exaltavam a fábrica, as chaminés, a vida corrida, a urbanização, mas neste interim, se mantinham no bairrismo. Observamos um fragmento do poema de Mario de Andrade, Inspiração de 1922:

São Paulo! Comoção da minha vida...

Os meus amores são flores feitas de original...

Arlequinal!... Traje de losangos... Cinza e Ouro...

Luz e bruma... Forno e inverno morno...

Elegâncias sutis sem escândalos, sem ciúmes...

Perfumes de Paria... Arys!

Bofetadas liricas no Trianon... Algodoal!

São Paulo! Comoção de minha vida...

Galicismo a berrar nos desertos da América!

A inspiração vem da Sáo Paulo da vida do autor, cidade levada a todos e enaltecida, a cidade da transformação, da mudança, do modernismo. Pinto comenta que a "Pauliceia Desvairada, simbolo da nova cultura nacional, escrito em 1921, é a oportunidade de casar seus anseios estéticos de dinamismo na poesia com a lição recebida dos unanimistas e dos futuristas" (2001, p. 442).

Mas esta ação se concentra no adulto, no homem formado, letrado, culto. Toda ação da Semana de Arte Moderna encontra-se distante da criança. Procura unir os Brasis, mas já tocando o coraçáo e alma dos adultos. Não sejamos tolos em ignorar o efeito devastador da mobilização de nobres almas em busca de uma unificação desta cultura nascente, 
entretanto de forma concisa e mais presente, uma revista vinda da "decrépita" capital teve mais sucesso na formação de uma transformação, pois como coloca Merlo o Tico-Tico: "foi um veículo de transmissáo de questóes sociais e educacionais para o púbico leitor, além dos textos ilustrados e quadrinhos instrutivos e recreativos utilizados pelas crianças antes mesmos da idade escolar"(2005, p. 87).

\section{CONCLUSÃO}

Para se formar uma nação, deve-se pensar primeiro nos pequenos. Augusto comenta que a origem no nome da revista não está vinculada ao passarinho de mesmo nome: "mas nas escolas de primeiras letras, então chamadas 'escolas de tico-tico', a acepção registrada pelo Aurélio, que também aponta a palavra como sinônimo de gente miúda" $(2005,07)$. Esta ligação com os pequenos explica a importância do periódico semanal que vinha da Rua do Ouvidor quando se analisa a influência no ensino. Não devemos negar o objetivo financeiro, visto que sem a resposta do público, náo poderia se ter tantos exemplares disponíveis.

Fica claro e evidente que tudo deveria ser voltado para o ensino lúdico, cada conto, cada lenda, cada quadrinho colocado, as respostas do Dr. Sabe-tudo, cada lição do Vovô, as seções, tudo deveria girar entorno da formação dos leitores. Mas, se por acaso, algum adulto aprendesse algo, seria então um grande lucro. $\mathrm{O}$ patriotismo deveria vir com o tempo, com o valor a nação, aos heróis, as grandes figuras que ajudaram a formar o grande Brasil.

Sem regionalismo, sem bairrismo, mas com a intenção maior e ampla. O ser adulto deveria levar consigo os ensinamentos da revista e assim, ao se deparar com uma atitude errada, assumir a posiçáo de defender os bons costumes. Ao longe estamos da Semana de Arte Moderna, ao longe estamos do modernismo reinante na industrial paulistana, ao longe estamos de uma sociedade dita igualitária, mas que separa todos em bairros. Chiquinho e jagunço ganham um amigo, mesmo este sendo de uma condiçáo inferior, a amizade foi formada, o menino referência da revista se despontava.

A superação do modernismo paulistano não ocorreu tão rapidamente, assim, como a revista, foi conquistando seu espaço e suplantando os adversários e precursores, os modernistas fizeram o mesmo. Entretanto sem o vanguardismo da revista, seria uma tarefa árdua para jovens intelectuais implantarem nas mentes consideradas incultas conceitos amplos e algumas vezes abstratos. O Tico-Tico ensinou a cultivar o hábito da leitura, de buscar entender o mundo que rodeava os pequenos e assim, entenderem conceitos mais amplos.

Se não era modernista, o Tico-Tico era moderno, um periódico voltado para sua época e condição, algo único e distinto. Olhava mais o presente do que para o futuro, pois esta é a condição daquele que procura trabalhar com o ensino dos pequenos. Feito o seu trabalho, o bastão é passado adiante e neste caso, os paulistas reclamaram para si a condição de continuar o trabalho iniciado, procurando a unicidade da nação, sob seus aspectos modernistas. 


\section{FONTES}

Tico-Tico - Anno XV, Rio de Janeiro, quarta-feira, 6 de janeiro de 1920, nº 01. Acervo digital da Hemeroteca Digital Brasileira, Biblioteca Nacional, Rio de Janeiro.

Tico-Tico - Anno XVI, Rio de Janeiro, quarta-feira, 23 de fevereiro de 1921, $\mathrm{n}^{\circ}$ 803. Acervo digital da Hemeroteca Digital Brasileira, Biblioteca Nacional, Rio de Janeiro.

Tico-Tico - Anno XVI, Rio de Janeiro, quarta-feira, 7 de dezembro de 1921, $n^{\circ} 844$. Acervo digital da Hemeroteca Digital Brasileira, Biblioteca Nacional, Rio de Janeiro.

Tico-Tico - Anno XVI, Rio de Janeiro, quarta-feira, 28 de dezembro de 1921, $n^{\circ} 847$. Acervo digital da Hemeroteca Digital Brasileira, Biblioteca Nacional, Rio de Janeiro.

Tico-Tico - Anno XVII, Rio de Janeiro, quarta-feira, 22 de fevereiro de 1922, nº 855. Acervo digital da Hemeroteca Digital Brasileira, Biblioteca Nacional, Rio de Janeiro.

Tico-Tico - Anno XVII, Rio de Janeiro, quarta-feira, 1 de março de 1922, n 856. Acervo digital da Hemeroteca Digital Brasileira, Biblioteca Nacional, Rio de Janeiro.

Tico-Tico - Anno XVII, Rio de Janeiro, quarta-feira, 12 de abril de 1922, n 862. Acervo digital da Hemeroteca Digital Brasileira, Biblioteca Nacional, Rio de Janeiro.

Tico-Tico - Anno XVII, Rio de Janeiro, quarta-feira, 19 de abril de 1922, $n^{\circ} 862$. Acervo digital da Hemeroteca Digital Brasileira, Biblioteca Nacional, Rio de Janeiro.

Tico-Tico - Anno XVII, Rio de Janeiro, quarta-feira, 26 de abril de 1922, n 864. Acervo digital da Hemeroteca Digital Brasileira, Biblioteca Nacional, Rio de Janeiro.

Tico-Tico - Anno XVII, Rio de Janeiro, quarta-feira, de 3 de maio de 1922, n 865. Acervo digital da Hemeroteca Digital Brasileira, Biblioteca Nacional, Rio de Janeiro. 


\section{REFERÊNCIAS}

ANDRADE, Mario de. Pauliceia Desvairada. São Paulo: Landmark, 2003.

AUGUSTO, Sergio. O Tico-Tico sem fubá. In: VERGUEIRO, Waldomiro; SANTOS, Roberto Elísio dos. O Tico Tico - Centenário da Primeira Revista de Quadrinhos do Brasil. Vinhedo, SP: Opera Graphica Editora, 2005.

BARBOSA, Alexandre, História e Quadrinhos: A Coexistência da Ficção e da Realidade in VERGUEIRO, Waldomiro e RAMOS, Paulo (org). Muito além dos quadrinhos. São Paulo: Devir, 2009.

EISNER, Will. Quadrinhos e arte sequencial. São Paulo: Martins Fontes, 1999.

. Narrativas Gráficas, São Paulo: Devir, 2005.

GOMES, Ângela de Castro e HANSEN, Patrícia Santos (org.). Intelectuais Mediadores: práticas culturais e ação política. 1 ed., Rio de Janeiro: Civilização Brasileiro, 2016.

HANSEN, Patrícia Santos. Brasil, um país novo: literatura cívico-pedagógica e a construção de um ideal de infância brasileira na Primeira República. 2007. Tese (Doutorado em História Social) - Faculdade de Filosofia, Letras e Ciências Humanas, Universidade de São Paulo, São Paulo, 2007. doi: 10.11606/T.8.2007.tde-12022008-111516. Acesso em: 13 mar. 2017.

LUYTEN, 2005.

MCCLOUD, Scott. Desvendando os quadrinhos. São Paulo: M. Books do Brasil Editora LTDA, 2005.

MERLO, Maria Cristina. O Tico-Tico um marco nas histórias em quadrinhos no Brasil (1905-1962). Anais do II Encontro Nacional da Associaçáo Brasileira de Pesquisadores de História da Mídia - Alcar. Florianópolis, UFSC, 2004. Disponível em:<http://www.ufrgs. br/alcar/encontros-nacionais-1/encontros-nacionais/2o-encontro-2004-1>. Acesso em: 12 jul. 2017.

PINTO, Maria Inez Machado Borges. Urbes industrializada: o modernismo e a pauliceia como ícone da brasilidade. Rev. bras. Hist., São Paulo, v. 21, n. 42, pp. 435455, 2001. Disponível em: <http://www.scielo.br/scielo.php?script=sci_arttext\&pi$\mathrm{d}=$ S0102-01882001000300009\&lng=en\&nrm=iso>. Acesso em: 14 fev. 2017. http:// dx.doi.org/10.1590/S0102-01882001000300009.

SEVCENKO, Nicolau. Literatura Como Missão: tensóes sociais e criação cultural na Primeira República. São Paulo: Brasiliense, 1999.

SILVA, Diamantino. OTico-Tico que Eu Conheci in: VERGUEIRO, Waldomiro; SANTOS, Roberto Elísio dos. O Tico Tico - Centenário da Primeira Revista de Quadrinhos do Brasil. Vinhedo, SP: Opera Graphica Editora, 2005.

SILVEIRA, Guilherme Lima Bruno. Os balóes n'O Tico-Tico: esqueceram de desenhar? A 
revista História, Movimento e Reflexão. Barretos, SP, v. 1, n. 1, pp. 1-15, 2013. Disponível em: <http://revistadigital.unibarretos.net/index.php/historia/issue/view/3>. Acesso em: 14 jul. 2017.

VELLOSO, Mônica Pimenta. História \& Modernismo. 1 ed., Belo Horizonte: Autêntica, 2010

VERGUEIRO, Waldomiro; SANTOS Roberto Elísio dos. O Tico Tico - Centenário da Primeira Revista de Quadrinhos do Brasil. Vinhedo, SP: Opera Graphica Editora, 2005.

Recebido: 31/9/2017 Aceito: 6/10/2017 